\title{
The medical student elective in Africa: advice from the field
}

\author{
Ellen M. Einterz MD
}

$\mathrm{F}$

or European or North American medical students, the decision to pursue an elective in Africa will not be taken lightly. Travel is expensive; finding an appropriate hospital may be difficult; health and security risks must be considered, language barriers overcome, and comfort and convenience deferred. Students who surmount these hurdles will find them a fitting warm-up for the rocky road ahead.

Visas, vaccinations, malaria prophylaxis, what to pack and not to pack - students returning from an elective, and their schools of medicine, can provide excellent guidance on these issues. ${ }^{1-7}$ The advice offered here comes from the continent of destination rather than departure, and is based on 25 years of experience teaching and practising clinical medicine and public health in rural west and central Africa.

The first step is to choose the right destination. Africa is a a large and diverse continent. As a consequence, there are several different kinds of elective opportunities. One source for electives is collaborative programs between Western universities and hospitals and their counterparts in Africa. These partnerships provide elective opportunities for students interested in working in teaching hospitals or research settings. Additional sources are mission organizations, which tend to be in more rural areas and focus on grassroots care, and nongovernmental organizations that specialize in individual services, such as ophthalmology or rehabilitative plastic surgery, and provide a more targeted elective experience. Communicating frankly with the person in charge and with other students who have completed the elective under consideration is a good way of knowing whether a particular site is a good fit.

African hospitality is justly legendary, and even in areas where xenophobia is deeply rooted, hospitality is usually the rule. However, this does not prevent Africans from having preconceived notions about what to expect from foreigners. The newly arrived student may be regarded as an altruistic humanitarian, adventurer, earnest apprentice, full-fledged doctor, profligate gadfly or just a curiosity - much depends on the community's experience with students in the past.

\section{Professionalism is key}

Students who come as tourists will be tolerated as tourists. Those, in contrast, who come prepared to share the lives and help shoulder the burdens of patients and fellow health care workers and who, from the beginning, consider their electives a job deserving the same discipline as a job in their home countries, will be embraced. Discussing learning objectives with supervisors and knowing what is expected of them will help students take their places as full members of the team as quickly as possible. A willingness to work nights and week-

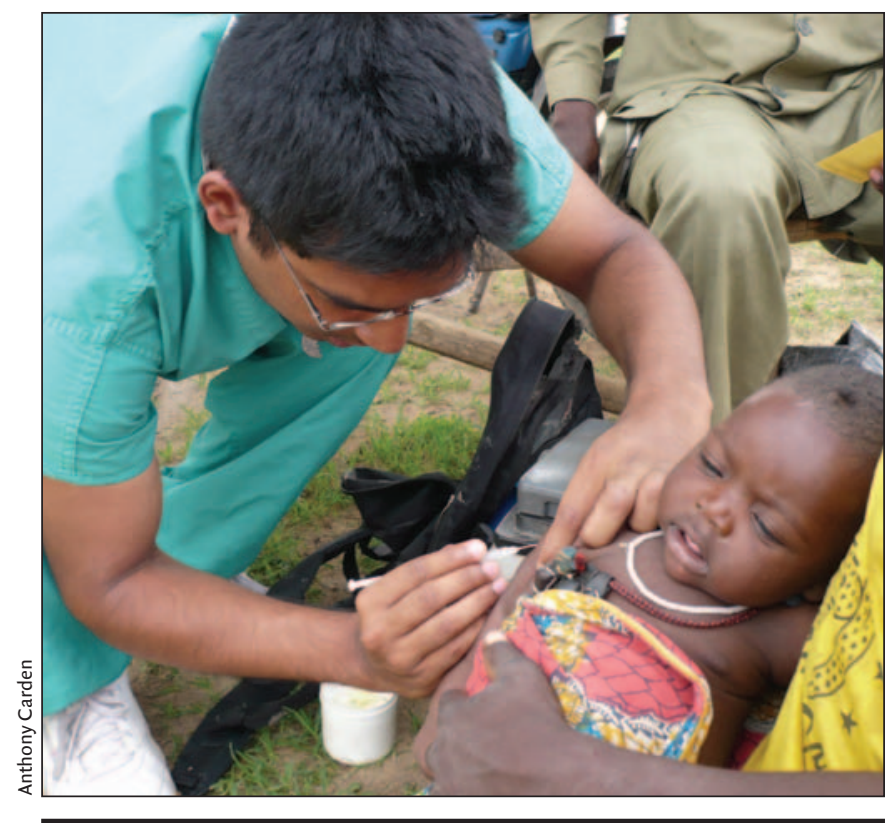

A student on his elective in Kolofata District, Far North Province, Cameroon, administering a vaccine to an infant.

ends as needed and to learn new skills without overstepping known limits will also help students to integrate into the health care team.

It may come as a surprise to most students that they, not their host communities, will probably be the main beneficiaries of an African elective, at least in the short term. However, students can rest assured that their enthusiasm, goodwill and readiness to work and to learn will have a positive impact on those around them. The host hospital may be low-tech, its clients poor and uneducated and its facilities unpolished, but it is providing a valuable service to the people who use it. The knowledge, experience and expertise of its personnel should not be underrated, and elective students will have the opportunity to learn from everyone. Their primary mentors and supervisors will probably be physicians, but others can also teach them a great deal. Nurses and midwives in Africa often perform work undertaken in other places only by physicians. They routinely consult and prescribe, operate, administer anesthesia and admit patients to hospital. Skilled, pragmatic and sometimes a little disdainful of doctors, these nurses and midwives can be excellent teachers. Even hospital cleaners, drivers, night watchmen and groundskeepers will teach students a thing or two if they are willing to listen. As elsewhere,

Ellen Einterz is Medical Director of the Kolofata District Hospital and Chief Medical Officer of the Kolofata Health District, Kolofata, Cameroon. 
students will learn more from their patients than from all of these others put together.

In most cases, mentors will view students in 2 ways: on the one hand, as yet another predator of precious time he or she scarcely has left to give, and on the other hand, as a source of delight and maybe even inspiration. Unwittingly, students will add to their supervisors' repository of anecdotes. My own reminiscences range from one student who

\section{"I learned what it is to be a doctor.} There's so much more to it than taking care of sick people." - a student's thoughts after completing a medical elective in Africa

called me urgently to examine a comatose toddler (who in fact was sleeping) to the student who, clutching an infant in one arm and raising the other fist toward a trio of vultures on a hospital roof, shouted, "You're not getting any of them!" As time permits, students should share their thoughts and impressions with their supervisors; their fresh perspectives can only be enriching.

\section{Personal safety and contingency plans}

Before leaving home, it is always a good idea to photocopy passports, visas, driver's licenses and insurance cards and keep them in a safe place after arriving in Africa. Whether in the hospital or elsewhere, being prudent about personal safety is a must. If the hospital cannot provide gloves and safety glasses, students should bring their own. It is also important to find out in advance how to obtain prophylactic antiretroviral treatment in case of accidental exposure to contaminated fluids.

Outside the hospital, visitors should approach food, drink and leisure activities with healthy skepticism. Motorcycles are a popular means of transportation in Africa, and helmets are no less protective here than elsewhere. Although local drivers may not wear helmets, I would strongly caution students to use them and to drive a motorcycle only if they have a driver's licence recognized by the host country.

"I'm afraid of being robbed or raped," one student admitted to me, explaining why, a few weeks before she was due to leave the United States, she was having second thoughts. Robbery and rape happen in every country every day, but the wise visitor to a foreign country will be extra cautious. To avoid being seen as easy prey for unscrupulous hustlers, it is essential to avoid flaunting money, possessions or purchasing power, and to abstain from casual sex. It is also best to avoid taking pictures without the permission of the person being photographed. To help students prepare for possible pitfalls, Dr. Robert Einterz, director of Indiana University's partnership with Moi University in
Kenya, advocates predeparture orientation sessions in which students role-play scenes they might experience on arrival. For example, a student arriving at the airport and going through customs is approached by a young man who offers to carry her suitcase. Though he appears and may be genuinely helpful, it is also possible that his real intention is to steal the suitcase, to lure her into his car or perhaps to embarrass her into paying him an exorbitant fee for his baggage-handling service.

Catastrophes such as floods, earthquakes, riots and epidemics are seldom easy to predict, but some basic precautions can be taken. Students travelling to a country with precarious political stability can avoid scheduling electives during election periods and stay away from political rallies or other mass demonstrations. Being aware of contingency plans for coping with an eventual disaster and informing relevant embassies of travel plans and local contact information are the hallmarks of a wise traveller. Visitors may be required to register with the local police, but if not, it is a good idea to ask to be introduced to the government and law enforcement officials in the area.

A certain instability underlies many ordinary things in much of Africa, and it is important to expect the unexpected. The electrical supply is unstable, Internet connections can be erratic, water pipes run dry, roads that are passable one day are washed out the next, and posted timetables tend to be vague indications at best. We take it in stride when things don't go as planned. Having a plan B - and perhaps C and D - is always a good idea.

\section{Cultural sensitivity}

To gain the most from the elective experience, students should discover how health and sickness fit into daily life within the communities they serve. What happens in the home when someone becomes sick? What kind of treatment is sought first and what influences a family's decision to bring a sick relative to hospital? What are the costs of ill

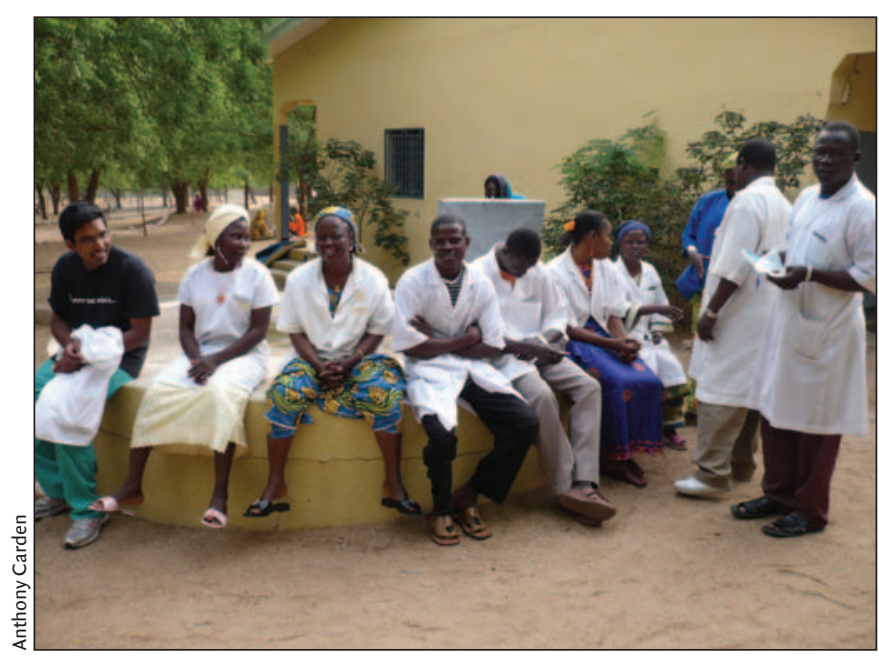

Hospital nurses with a student (left) on an elective in Kolofata,

Cameroon, awaiting the start of morning rounds. 
health in terms of money, travel, time and lost labour for the patient and for his caregivers? What does the community believe to be the cause of sickness in general or of a disease in particular?

\section{"What I learned in Cameroon will be beneficial no matter what practice I choose for the future.”- a student's perspective on a medical elective in Africa}

Language is culture, and Africa has a rich abundance of both. In many places, a country's official language is spoken by a minority of the population, and to be effective, health care workers must be competent in one or several local languages. Students are unlikely to become fluent in these languages during their elective period, but within the first week they should be able to master greetings, numbers and some basic questions and answers. This will help them to feel more a part of the community, whose members will be flattered and delighted by the effort. However, a word of warning: once patients or neighbours hear a student speak a few words, they will likely start talking rapidly and at length, assuming the visitor knows exactly what they are saying.

\section{Read, write and keep in touch}

Reading is important. Tropical medicine is famously regional, and even within the same small country, some diseases that are prevalent in one province may be absent from another. Students should find out what the most common diseases are in their regions and brush up on them. Learning a little about the big vertical programs such as the Expanded Program on Immunization and the Global Fund to Fight AIDS, Tuberculosis and Malaria will provide valuable insight. I recommend that students make a list of cases seen throughout the day and, in the evening, find a book, article or website where they can read about the disease, drug, procedure, laboratory test, ultrasound finding, public health threat or whatever piqued their curiosity that day.

Students will find that keeping a journal or writing letters is useful. Writing down the details, thoughts and feelings as they happen will help them to consolidate their impressions and remember them more clearly later. In addition, planning and executing a project - a final report, a newspaper or journal article, an oral presentation or a research study - is a particularly good way of providing the pillars and beams that will strengthen a relatively amorphous experience.

Finally, I encourage students to keep in touch after completing their electives, to share the results of research so that their work might benefit the community, to send copies of photographs, to update erstwhile colleagues of their activities or simply to let the hosts know they have returned home safely. Students who worked hard, cared deeply and engaged fully during their rotations will realize wistfully, but without regret, that they brought a little of Africa home with them while leaving a part of themselves behind.

This article has been peer reviewed.

Competing interests: None declared.

\section{REFERENCES}

I. Shiner D, Miranda J. Electives in the developing world. McGill J Med 2004;7. Available: www.medicine.mcgill.ca/mjm/issues/v07no2/commentaries/commentaries .htm (accessed 2008 Feb I2).

2. Imperato PJ. A third world international health elective for U.S. medical students: the 25-year experience of the State University of New York, Downstate Medical Center. J Community Health 2004;29:337-73.

3. Radstone SJJ. Practising on the poor? Healthcare workers' beliefs about the role of medical students during their elective. JMed Ethics 2005;31:109-Io.

4. Elswood R. Babies and bananas: on foot in Rwanda. BMJ I979;2:1559-6I.

5. Northrup RS. Preparing students for overseas electives. Acad Med I991;66:92.

6. Heck JE, Wedemeyer D. A survey of American medical schools to assess their preparation of students for overseas practice. Acad Med I99I;66:78-8I.

7. Hope R. The medical student's guide to essential international health and development. London: International Health and Medical Education Centre, University College London; 2004. Available: http://student.bmj.com/international/ElectivePack .pdf (accessed 2008 Apr 7).

Correspondence to: Dr. Ellen M. Einterz, Hôpital de District de Kolofata, B.P. III, Mora, Extrême-Nord, Cameroon; emeinterz@yahoo.com 